\title{
Reflexões sobre a reforma gerencial brasileira de 1995
}

\author{
Luiz Carlos Bresser Pereira
}

Revista do

Serviço

Público

Ano 50

Número 4

Out-Dez 1999

Luiz Carlos

Bresser Pereira, professor titular de economia da

Fundação Getúlio

Vargas/SP e ex-

Ministro da

Administração e Reforma do

Estado, da

Ciência e

Tecnologia e da

Fazenda ser considerada como um verdadeiro êxito. ${ }^{1}$ Como ministro encarregado de sua realização, farei, neste artigo, algumas reflexões sobre o assunto. Em primeiro lugar, definirei brevemente a reforma gerencial, e, numa segunda parte, tentarei responder a algumas perguntas: por que o governo resolveu propor uma reforma gerencial do serviço público incluindo a reforma da Constituição, já que não fazia parte da agenda política do país nem dos temas da campanha presidencial de 1994? Por que as idéias gerais de uma reforma administrativa do serviço público foram aprovadas pela opinião pública, e por que as idéias mais específicas propostas no Plano Diretor da Reforma do Aparelho de Estado foram adotadas pelos altos funcionários do serviço público brasileiro? Por que a emenda constitucional foi aprovada pelo Congresso, enquanto as duas outras emendas importantes — da previdência social e da reforma tributária - não o foram? Qual a importância da existência de uma demanda prévia da sociedade? Ou será que uma concepção e desenho mais corretos tornaram-se fatores diferenciais em relação às outras reformas? Ou ainda, será que o 
caráter democrático do debate nacional que a emenda provocou teve importância? Como foram identificados, e eventualmente neutralizados, os adversários da reforma? Quais alianças políticas foram efetuadas? E quais os compromissos realizados? Quão significativos foram uns e outros?

\section{Uma reforma gerencial}

A Reforma Gerencial de 1995 está substituindo a atual administração pública burocrática, misturada a práticas clientelistas ou patrimonialistas, por uma administração pública gerencial, que adota os princípios da nova gestão pública (new public management). As reformas administrativas na América Latina costumam ser apenas mudanças ad hoc no organograma da administração, que são implementadas no momento em que o novo governo toma posse. Essas são falsas reformas que não envolvem mudanças institucionais significativas. Na verdade, foram apenas duas as verdadeiras reformas administrativas desde a construção dos estados nacionais modernos: a Reforma Burocrática ou Reforma do Serviço Público e a Reforma Gerencial da Administração Pública. A primeira, que foi analisada por Weber, diz respeito à formação de um serviço público profissionalizado; ocorreu em meados do século XIX na Europa ocidental, no início do século XX nos EUA e na década de 30 no Brasil. A reforma gerencial, que flexibiliza os processos e os regulamentos burocráticos, conferindo um grau mais elevado de autonomia e de accountability às agências governamentais e aos seus gerentes, é a segunda: é um novo fenômeno histórico, que ganhou força nas últimas duas décadas, quando as pessoas começaram a perceber que uma das razões da atual crise fiscal do Estado era a ineficiência estrutural da administração pública burocrática.

A Reforma Gerencial de 1995 foi definida inicialmente no Plano Diretor da Reforma do Aparelho de Estado (1995) ${ }^{2}$. Nesse documento, após se constatar a ineficiência do serviço público existente no Brasil, desenvolve-se um quadro teórico para a reforma, inspirado nas reformas gerenciais que estão sendo implementadas desde a década de 80 em certos países da OCDE, e particularmente na Grã-Bretanha. A reforma envolve: a) a descentralização dos serviços sociais para estados e municípios; b) a delimitação mais precisa da área de atuação do Estado, estabelecendo-se uma distinção entre as atividades exclusivas, que envolvem o poder do Estado e devem permanecer no seu âmbito, as atividades sociais e científicas, que não lhe pertencem e devem ser transferidas para o setor público não-estatal, e a produção de bens e serviços para o mercado; c) a distinção entre as atividades do núcleo estratégico, que devem ser efetuadas por políticos e altos funcionários, e as atividades de serviços, que podem ser objeto de contratações externas; d) a separação entre a formulação de 
políticas e sua execução; e) maior autonomia para as atividades executivas exclusivas do Estado que adotarão a forma de agências executivas; f) maior autonomia ainda para os serviços sociais e científicos que o Estado presta, que deverão ser transferidos para (na prática, transformados em) organizações sociais, isto é, um tipo particular de organização pública nãoestatal, sem fins lucrativos, contemplada no orçamento do Estado - como no caso de hospitais, universidades, escolas, centros de pesquisa, museus, etc.; g) assegurar a responsabilização (accountability) por meio da administração por objetivos, da criação de quase-mercados e de vários mecanismos de democracia direta ou de controle social, combinados com o aumento da transparência no serviço público, reduzindo-se concomitantemente o papel da definição detalhada de procedimentos e da auditoria ou controle interno — os controles clássicos da administração pública burocrática que devem ter um peso menor.

Uma característica essencial da reforma do Estado brasileira, prevista no Plano Diretor, mas anterior a ele, como também o é a descentralização para estados e municípios de serviços sociais, foi a decisão de privatizar as empresas estatais que produzem bens e serviços para o mercado. O Plano Diretor previa ainda uma mudança que estava apenas começando no setor público: a terceirização das atividades de apoio para o setor privado, desde serviços simples como segurança e limpeza, até complexos como consultoria e serviços de computação. Enquanto se terceirizavam para o setor privado essas atividades, a proposta talvez mais inovadora do Plano Diretor era transferir as atividades sociais e científicas, que a sociedade acredita devam ser total ou parcialmente financiadas pelo Tesouro, para o setor público não-estatal, transformando-as em organizações sociais. Por outro lado, grande ênfase era dada no Plano Diretor ao fortalecimento do núcleo estratégico do Estado, onde as decisões de políticas são tomadas por políticos e altos funcionários.

\section{Uma história de sucesso}

Vários indicadores mostram que a reforma gerencial brasileira é uma história de sucesso, pelo menos por enquanto. Em primeiro lugar, implementaram-se os dispositivos básicos necessários para uma reforma gerencial: a emenda constitucional que a imprensa e a opinião pública chamaram de reforma administrativa foi aprovada pelo Congresso com pequenas mudanças em relação à proposta original do governo; as leis que definem as duas principais instituições organizacionais da reforma — agências executivas e organizações sociais — foram adotadas; estabeleceram-se as normas dos contratos de gestão, que definem os indicadores de desempenho a serem alcançados por cada organização depois de ganhar 
maior autonomia; alterou-se profundamente a Lei do Regime Jurídico Único, que estabelecia uma série de privilégios e um regime trabalhista único para todos os servidores públicos, quer desempenhassem funções do núcleo estratégico ou não; definiu-se uma nova política de recursos humanos, estabelecendo que apenas os membros das carreiras típicas de Estado, envolvidos em atividades exclusivas do mesmo, deveriam continuar a ser recrutados anualmente - visto que as atividades de apoio devem ser terceirizadas, e as atividades sociais e científicas transferidas para o setor público não-estatal, suspendendo-se a contratação direta pelo Estado - e que esses servidores deveriam ser bem pagos e bem treinados.

Em segundo lugar, escolheu-se, com ampla aceitação, a Gestão pela Qualidade Total (Total Quality Control) como principal estratégia de gerenciamento a ser adotada pelas organizações do Estado. Uma reforma gerencial precisa de uma estratégia de gestão. $\mathrm{O}$ controle de qualidade total é uma estratégia empresarial particularmente adequada ao gerenciamento público, por adotar vários critérios de excelência além da simples taxa de lucros, que, por definição, não existe no governo. No início da década de 90, houve uma primeira tentativa de introdução da gestão pela qualidade na administração federal brasileira. Formou-se um grupo de fortes adeptos dessa estratégia, mas a tentativa falhou, porque as diferenças entre as administrações pública e privada não haviam sido bem definidas e, mais particularmente, porque a tentativa não se inseria num modelo global de reforma. Aos altos funcionários faltava a autonomia necessária para adotar os meios mais adequados de alcançar os resultados desejados.

Dentro do contexto da Reforma Gerencial de 1995, a gestão pela qualidade total ganhou vida nova. As diferenças eram claras: enquanto a administração privada é uma atividade econômica controlada pelo mercado, a administração pública é um empreendimento político, controlado politicamente. Na empresa privada, o sucesso significa lucros; na organização pública, significa o interesse público. É possível transferir os instrumentos de gerenciamento privado para o setor público, mas de forma limitada. Pode-se descentralizar, controlar por resultados, incentivar a competição administrada, colocar o foco no cliente, mas a descentralização envolve o controle democrático, os resultados desejados devem ser decididos politicamente, quase-mercados não são mercados, o cliente não é apenas cliente, mas um cliente-cidadão revestido de poderes que vão além dos direitos do cliente ou do consumidor. Com a explicitação dessas diferenças e o aumento da autonomia e da responsabilização que os dirigentes estão assumindo no âmbito da reforma, o controle de qualidade na administração pública ganhou legitimidade e tornou-se a estratégia gerencial oficial para a implementação da reforma. 
Em terceiro lugar, a opinião pública, as elites políticas e, sobretudo, os altos funcionários estão apoiando a reforma. De acordo com várias pesquisas de opinião, cerca de $75 \%$ da população aprovou a emenda constitucional da reforma administrativa. Cerca de $80 \%$ dos altos funcionários aprovaram não apenas a emenda, como mais especificamente as propostas do Plano Diretor da Reforma do Aparelho de Estado. Esse fato foi verificado numa pesquisa nacional realizada entre formadores de opinião no final de 1997, que evidenciou que o segundo grupo mais favorável à reforma era o grupo dos altos funcionários — sendo o primeiro constituído pelos empresários, e o terceiro, pelos jornalistas, seguidos pelos intelectuais e finalmente pelos líderes sindicais, que a aprovavam menos, mas mesmo assim aprovavam. Em 1998, uma pesquisa sobre a reforma realizada junto a funcionários de nível médio mostrou um apoio semelhante. ${ }^{3}$ Apenas um setor importante da alta administração pública brasileira não revelou apoio à reforma, embora também não tenha demonstrado resistência: o Poder Judiciário. Fiz várias tentativas de falar e debater com juízes e promotores, mas sem sucesso. Logrei conversar com juristas do Direito Administrativo, mas suas reações foram antes negativas que positivas. Receberam, entretanto, com grande interesse o trabalho teórico que fundamenta, no plano do Direito, a reforma: "Cidadania e Res Publica: A Emergência dos Direitos Republicanos". ${ }^{4}$

Em quarto lugar, os estados e as principais cidades estão adotando os novos dispositivos e práticas da reforma gerencial. A separação entre atividades exclusivas do Estado e serviços sociais e científicos que o Estado decide incluir no seu orçamento está sendo adotada de forma cada vez mais freqüiente. Organizações sociais estão sendo criadas em vários estados e em alguns municípios mais importantes, embora, em alguns casos, com certas distorções em relação ao projeto inicial. Programas de qualidade total estão surgindo no conjunto do país.

Em quinto lugar, as novas idéias e expressões, que foram introduzidas ou enfatizadas pela reforma - tais como reforma gerencial, atividades exclusivas do Estado, núcleo estratégico do governo, agências executivas, organizações sociais, contratos de gestão, indicadores de desempenho - entraram no vocabulário dos altos funcionários de Brasília e tornaramse um importante tema nas escolas de governo e de administração pública brasileiras.

Em síntese, a Reforma Gerencial da Administração Pública Brasileira, lançada em 1995, avançou nas três dimensões previstas pelo Plano Diretor: a institucional, a cultural e a gerencial. Criaram-se novas instituições, surgiu uma nova visão da administração pública, e novas práticas gerenciais estão começando a ser adotadas. Avaliando a reforma, Indermit Gill, do Banco Mundial, escreveu um artigo com um título sugestivo: “Alguns 
Determinantes de Sustentabilidade das Reformas da Administração Pública. Ou, Por Que Eu Estou Otimista em Relação à Reforma Administrativa no Brasil". 5

Por outro lado, as duas outras reformas — a tributária e a da previdência social — que há muito constavam da agenda política do país, não tiveram o mesmo destino. A emenda constitucional da previdência social, que terminou sendo aprovada pelo Congresso no final de 1998, era apenas a sombra do projeto original do governo. A reforma tributária apresentada em 1995 foi finalmente abandonada pelo próprio governo, que, apenas no final de1998, apresentou, sem muita precisão, um novo projeto de emenda. Como explicar resultados tão diferentes? Onde reside o segredo do sucesso desta reforma?

De acordo com minha experiência, a aprovação de grandes reformas depende de quatro fatores: necessidade, concepção e desenho, persuasão democrática e alianças. Há necessidade quando a reforma responde a uma demanda social real. O desenho adequado da reforma, isto é, o fato de que o texto ou o conteúdo das novas instituições propostas respondam efetiva e claramente aos objetivos visados, é essencial para sua aprovação. Em terceiro lugar, nas democracias, as reformas dependem de um debate nacional pelo qual a opinião pública possa ser persuadida. E em quarto, para conseguir o apoio dos políticos no Congresso, é necessário, além da aprovação da opinião pública, estabelecer alianças estratégicas.

\section{Responder a uma demanda social real}

O primeiro requisito para o êxito de uma reforma é que ela responda a uma demanda social real (embora possivelmente oculta). Esse foi o caso da Reforma Gerencial Brasileira de 1995, no início do governo Fernando Henrique Cardoso. A demanda existia, mas não estava clara para ninguém, não fazia parte da agenda política da nação e não fora um tema relevante na campanha presidencial de 1994. Havia, nas plataformas políticas dos dois principais candidatos, parcas referências à reforma da administração pública. O que existia de novo desde a segunda metade dos anos 80 era o consenso de que era necessário descentralizar os serviços sociais para os estados e de que as empresas estatais competitivas deveriam ser privatizadas. Além disso, reafirmavam-se as idéias da Reforma Burocrática de 1936: fortalecer a profissionalização da burocracia, tornar a administração mais impessoal e combater o clientelismo.

$\mathrm{Na}$ verdade, o Brasil estava vivendo um paradoxo. O Estado e sua burocracia haviam entrado em uma crise econômica e política de 
grandes proporções no início da década de 80. O modelo de desenvolvimento burocrático-capitalista, dirigido pelo Estado, estava envolvido em uma crise política, causada pela bancarrota do regime militar, e em uma crise econômica e financeira, que começou como uma crise da dívida externa, acompanhada por elevação dramática das taxas de inflação, mas que não demorou a revelar suas causas internas: uma crise fiscal do Estado e a exaustão da estratégia de crescimento nacional-desenvolvimentista. Nesse contexto, a burocracia do Estado, que tivera um papel dominante no regime militar, deveria ter perdido prestígio e influência, mas não foi isso que ocorreu. Com a transição para a democracia, em 1985, as políticas dos partidos de oposição que acabavam de assumir o governo, imaginando-se identificados com a democracia e a esquerda, revelavam, na verdade, tão ou mais acentuadamente que os partidos anteriormente no governo, uma ideologia burocrática, além de populista. O burocratismo renasceu, assim, das cinzas, na segunda parte da década de 80, ressaltando a existência do que Eli Diniz chamou de paradoxo: "a presença de um poder burocrático forte numa burocracia devastada" 6 . Mas, como os burocratas da época careciam de um projeto nacional mínimo, empenharam-se no rent-seeking, ou seja, na procura de vantagens e privilégios à custa do Estado. Uma busca coroada de êxito. Os principais dispositivos na Constituição de 1988 que tendiam para essa direção foram os artigos sobre a estabilidade e o sistema de previdência dos servidores públicos, complementados em nível apenas federal pela lei de 1991 sobre o Regime Jurídico Único dos Servidores Públicos. Criaram-se privilégios para os servidores públicos, garantindo-se-lhes estabilidade plena, uma aposentadoria precoce com vencimentos integrais equivalentes ao último salário e, na prática, sacramentando-se a renúncia à exigência de sua responsabilização (accountability) perante a sociedade.

Conseqüentemente, em janeiro de 1995, quando apresentei as primeiras idéias sobre a reforma da administração pública - atenuar a estabilidade plena que a Constituição garantia a todos os servidores públicos, aproximar os mercados de trabalho dos setores público e privado e usar organizações públicas não-estatais, sem fins lucrativos, para prestar os serviços sociais e científicos sustentados pelo dinheiro público - uma tempestade caiu sobre mim. O tema era novo e, portanto, ameaçador, pelo menos na aparência. A reação negativa foi quase universal. As pessoas não haviam tido tempo ainda para entender minhas propostas, pois a imprensa as apresentava de forma fragmentada, mas estavam contra. "O Ministro fala demais; deveria agir, fazer, em vez de falar”. Essa era uma crítica comum e autoritária, como se fosse possível reformar a Constituição e as leis de uma nação sem falar, sem debater idéias. 


\section{Um debate nacional}

Eu sabia, porém, que o que estava propondo era sensato e respondia a uma verdadeira demanda de uma sociedade insatisfeita com os serviços prestados pelos servidores públicos no Brasil. Portanto, embora sem ainda contar com o apoio do Presidente para a reforma constitucional da administração pública - ele apenas concordara que eu discutisse a questão com o público em geral e os políticos — resolvi ir adiante. A democracia brasileira é nova e talvez incompleta, por ser marcada pelo elitismo e pela falta de responsabilização, mas é uma verdadeira democracia, na qual as grandes mudanças políticas só podem ocorrer com o apoio da opinião pública. Portanto, o debate era essencial para que eu pudesse convencer as pessoas, conhecer suas reações e aproveitar algumas das idéias que surgiriam necessariamente da discussão. Eu tinha uma boa noção do que queria, mas sabia que essas idéias podiam ser aprimoradas com o debate.

O debate nacional sobre a reforma gerencial foi um debate de verdade. Eu e a minha equipe fizemos conferências no Brasil inteiro. Eu estava na imprensa todos os dias - imprensa essa que, ulteriormente, deu uma enorme contribuição para o debate. No início, os jornalistas distorciam as idéias, limitando-se sempre às mesmas poucas questões - particularmente à questão da estabilidade dos servidores — mas a mídia acabou desempenhando seu papel de veículo dos debates nacionais. Além disso, a maioria dos jornalistas passou gradualmente a defender as propostas, à medida que a opinião pública também se mostrava favorável.

Em um debate, certamente devemos ser prudentes e argutos. Evitar, sempre que possível, o confronto direto. Mas também é necessário ser claro e preciso sobre o que se pretende. É preciso, portanto, ter a coragem e a determinação de atacar diretamente o problema. Expressar francamente suas opiniões e propostas. Ouvir as críticas e estar disposto a aceitar algumas delas. Essa é uma estratégia arriscada. Pode-se argumentar que a alternativa seria esperar que o problema amadurecesse e que o desenho da reforma surgisse espontaneamente, a partir de algumas sugestões básicas. Essa pode ser uma boa estratégia quando se dispõe de muito tempo. Mas não é a minha maneira de fazer as coisas. A reforma da administração pública no Brasil era algo que precisava ser enfrentado, que pedia ação imediata. Criticar a situação existente, denunciar privilégios, pedir mudanças eram atitudes que não podiam ser adiadas. "Você pode perder o emprego se insistir com essas propostas", diziam-me freqüentemente as pessoas nos meus primeiros meses no cargo. Repetiam as advertências que já recebera 12 anos antes, quando fui Ministro da Fazenda (1987, em seguida ao colapso do Plano Cruzado e à moratória declarada pelo Brasil da sua dívida externa), em uma época em que o país enfrentava uma profunda crise financeira. Resolvi apresentar uma solução inovadora 
— e arriscada, segundo muitos — para a crise da dívida: a securitização

da dívida com um desconto. Respondi às novas advertências da mesma forma que fizera em 1987: "Qual é o valor de um cargo no governo se você não estiver fazendo o que deve ser feito?"7 Quando um país enfrenta tempos anormais, uma crise profunda, os ministros não podem ser apenas prudentes; precisam também ter a coragem de assumir riscos.

No entanto, eu sabia que o risco de fracasso seria reduzido na medida em que a população estivesse informada e persuadida. Nas democracias, as reformas dependem da opinião pública, que só pode ser conquistada por um debate nacional. Muitas pessoas no Brasil ainda acreditam que as reformas serão ou não aprovadas dependendo da força política do governo ou da racionalidade da reforma. Sem dúvida, ambas as variáveis são importantes, mas a mais importante é o apoio da opinião pública e das elites políticas, principalmente quando a reforma é importante e influi sobre o cotidiano das pessoas. Quando esse não é o caso, um debate técnico, complementado pelas alianças políticas necessárias, pode ser suficiente. Mas quando a reforma lida com instituições básicas, o apoio da opinião pública é crucial. Apoio este que virá se você for capaz de explicar suas idéias de forma simples e direta. Se estiver disposto a repetir inúmeras vezes os seus argumentos, e, obviamente, se as suas idéias fizerem sentido. ${ }^{8}$ $\mathrm{O}$ que nos leva à concepção ou ao desenho da reforma.

\section{Um desenho claro, nascido de uma avaliação precisa}

Uma reforma bem elaborada e competente depende de uma boa concepção ou um bom desenho. Este, por sua vez, será tanto melhor quanto mais preciso for o diagnóstico do problema e maior a competência jurídica e técnica dos reformadores. O diagnóstico básico estava claro para mim desde o início: a tentativa constitucional de 1988 de restaurar ou de instaurar plenamente no país a administração pública burocrática havia sido um desastre. Com a desculpa de que o pior inimigo a ser combatido era o clientelismo, o serviço público tornara-se rígido e ineficiente, carecia de um sistema de incentivos e punições e sofria do excesso de regulamentos e procedimentos estritos. Por outro lado, sempre em nome de um serviço público profissional e independente da política, e esquecendo o patrimonialismo burocrático-capitalista que sempre caracterizou o Brasil, privilégios de toda a sorte foram criados.

O retrocesso da administração pública para um sistema burocrático clássico, em um país cujo Estado enfrentava uma profunda crise, mas cuja administração havia sido capaz, nos 20 anos anteriores, de adotar uma estratégia gerencial pioneira e relativamente bem-sucedida para 
promover o crescimento econômico, envolveu enormes prejuízos: aumento insustentável das despesas com pessoal , deterioração dos serviços públicos e desmoralização dos servidores. Em vez de corrigir as distorções estatizantes e protecionistas da estratégia de crescimento anterior - um movimento que só começaria no início dos anos 90 - nos primeiros cinco anos do novo regime democrático, misturaram-se a reburocratização e a busca de privilégios, com terríveis consequiências para o prestígio de um serviço público que, até então, servira o país com competência e espírito público.

Partindo dessa idéia inicial, eu e a minha equipe envolvemo-nos em um diagnóstico complexo e difícil da situação do serviço público brasileiro, particularmente do federal, apesar de uma espantosa falta de dados a respeito. Não havia informações minimamente organizadas sobre o número de servidores públicos ou sobre os salários e sua evolução. Apenas sobre os custos totais envolvidos.

Mas não havia tempo a perder. A estrutura da reforma foi dividida em duas vertentes: a definição de uma emenda constitucional, que foi enviada ao Congresso em julho de 1995; e a elaboração dos fundamentos e diretrizes da reforma gerencial, definidos no Plano Diretor da Reforma do Aparelho de Estado, aprovado pelo Comitê de Reforma do Estado e pelo Presidente da República em setembro de 1995. O Plano Diretor incluía um diagnóstico da situação do serviço público brasileiro, um quadro teórico para a reforma gerencial e propostas específicas de reforma. O documento como um todo, que passou a ser central para a reforma, substanciava e completava a emenda constitucional.

Não me estenderei mais sobre a questão do Plano Diretor e sobre o modelo teórico de reforma que apresentava. Na primeira vez que expus essas idéias aos altos funcionários, a recepção foi extremamente positiva. Muitos comentaram que, finalmente, tínhamos uma reforma significativa da administração pública, o que demonstrava que os melhores servidores públicos brasileiros estavam esperando e pedindo uma reforma desse gênero. Essa recepção favorável repetiu-se inúmeras vezes, assegurando, afinal, seu apoio às idéias contidas no documento e na emenda constitucional.

Na elaboração da emenda constitucional, a questão da concepção ou do desenho foi decisiva, particularmente se compararmos a reforma administrativa com as reformas tributária e da previdência social. Quando o novo governo assumiu, em janeiro de 1995, duas crenças eram extremamente difundidas, inclusive entre os ministros. A primeira era a de que, considerando-se o grau extremo de pormenorização da Constituição brasileira, reformar a Constituição significava desconstitucionalizá-la, isto é, eliminar artigos e parágrafos do texto constitucional. A segunda era que o conteúdo básico de cada reforma já era conhecido: bastava escrevê-los. Nunca compartilhei da segunda opinião, que sofria o viés das atitudes arrogantes tão comuns entre pessoas recém-chegadas ao poder, mas a 
primeira parecia-me razoável. Frente a uma constituição extremamente detalhada, a melhor forma de emendá-la é eliminar dispositivos específicos e substituí-los, se necessário, por princípios gerais. É o que fizeram os autores da emenda da previdência social. É o que resolvi fazer, quando sentei pela primeira vez com três membros da minha equipe para começar a tarefa de emendar o capítulo da Constituição de 1988 relativo à administração pública.

Comecei pelo Artigo 37, seus itens e parágrafos. O processo era simples: corte este item, deixe esse outro, corte mais aquele, e assim por diante. Continuei dessa forma durante cerca de uma hora. Desconstitucionalizar era simples, direto. Seria mais simples ainda eliminar todo o capítulo sobre a administração pública. A maioria das constituições não incluem um capítulo sobre o assunto. De repente, porém, ocorreu-me um pensamento: "É fácil desconstitucionalizar, mas não vai dar certo. Os brasileiros costumam criticar o caráter pormenorizado da Constituição de 1988, mas, na verdade, gostam de constituições detalhadas. Querem ter todos os seus direitos claramente escritos. Se eu continuar nessa direção, os parlamentares vão dizer que o governo está pedindo um cheque em branco. E eles simplesmente não vão aprovar a reforma".

Decidi, portanto, interromper meu trabalho e começar tudo de novo, a partir de uma nova premissa: em vez de desconstitucionalizar, escreveria o mais claramente possível as mudanças que eu queria. Por exemplo, como a estabilidade deveria ser mais flexível. Em quais condições precisas os servidores públicos poderiam ser demitidos por excesso de quadros - o que teria importantes efeitos fiscais — ou por insuficiência de desempenho - o que estabeleceria as condições para um sistema de incentivos gerenciais no serviço público. Como, na questão da demissão, os servidores deveriam ser protegidos contra decisões políticas, mas não contra decisões técnicas. A tarefa era inteiramente diferente e muito mais complexa. Demorou cinco meses para ser completada. Exigiu criatividade, humildade para aceitar as boas idéias críticas que surgiram do debate nacional e competência jurídica para conhecer todos os problemas envolvidos e escrever um texto preciso. ${ }^{9}$

A decisão de abandonar a desconstitucionalização e optar por uma emenda tão ou mais detalhada que o texto original foi crucial. Impediu que o relator da reforma administrativa no Congresso (os relatores têm um poder imenso na aprovação de emendas constitucionais) fizesse o mesmo que o relator da reforma da previdência social, alguns meses depois. Como os autores do projeto haviam optado pela desconstitucionalização, esse relator declarou que o governo estava pedindo um cheque em branco do Congresso e resolveu fazer o que lhe parecia óbvio, a ele e à maioria dos seus colegas do Congresso: preencheu o cheque. Ao fazê-lo, desfigurou a 
reforma, reintroduzindo no texto constitucional todos os privilégios (direitos)

que a reforma tencionava eliminar. Ficou claro para mim, meses antes que isso acontecesse com a reforma da previdência social, que eu não poderia sofrer esse risco. A emenda teria que ter uma estrutura clara, destinada a produzir mudanças graduais e razoáveis. Cada artigo, cada parágrafo seria escrito da forma mais precisa e claramente fundamentada possível. Essa é provavelmente a principal razão pela qual o Congresso introduziu apenas algumas modificações menores na proposta original. A substância da emenda permaneceu intacta e, após um longo e difícil debate, foi aprovada. ${ }^{10}$

A concepção correta da proposta facilitou o debate nacional, que, por sua vez, contribuiu para a qualidade da concepção. O Brasil é um país democrático. Não é a democracia dos nossos sonhos, mas é uma democracia. Temos liberdade de expressão e de imprensa, um estado de direito, um Judiciário independente e um Congresso ativo que responde intensamente à opinião pública e a grupos de pressão. Era essencial persuadir a opinião pública. Então, durante os dois anos e meio de discussão da emenda no Congresso, tornei-me o advogado nacional da reforma. Levei o Plano Diretor e a emenda para todos os lugares, para todos os foros, debatendo, argumentando. Nesses debates, procurei ter uma mensagem simples e clara, em que os aspectos positivos — e não apenas os punitivos — da reforma também estivessem presentes.

A mídia desempenhou um papel essencial nesse processo. Os jornalistas apenas se interessavam pelos aspectos financeiros e de curto prazo. Seus temas prediletos eram a redução de quadros, o fim da estabilidade, o teto salarial que eliminaria alguns salários extremamente elevados. Pouco se interessavam pelos objetivos mais positivos, de médio prazo: maior papel para as organizações públicas não-estatais, aumento da eficiência, foco no cliente-cidadão, nova política de recursos humanos, nova política de concursos públicos. Mas consegui inserir progressivamente as novas idéias, e, aos poucos, começou a ficar claro que eu não era, como meus adversários sugeriam, o "carrasco dos servidores públicos", o "neoliberal impiedoso" ou o "defensor xiita do mercado", e sim que minha mensagem envolvia reconstruir o Estado, aumentar sua capacidade de desempenhar seu papel clássico de proteção dos direitos humanos, de defesa dos interesses da nação e garantia dos fundamentos macroeconômicos, assim como seu papel moderno de promoção da competitividade internacional do país e de proteção dos direitos sociais e dos direitos republicanos. Esses, que defini como sendo o direito de cada cidadão de que o patrimônio público seja utilizado para o interesse público, em vez de ser capturado por grupos de interesse, tornaram-se a peça central, fundamentando a reforma. 


\section{Estabelecer alianças e identificar os adversários}

Na luta para mudar as instituições, nunca estamos sós: há os adversários, que precisamos identificar claramente, e os aliados, que precisamos chamar o quanto antes para ajudar. Os adversários no Congresso e na sociedade eram conhecidos: os representantes do velho patrimonialismo, tão profundamente arraigado na sociedade brasileira, e do nem tão novo corporativismo de bases sindicais. A aliança entre estes dois extremos aparentes - o patrimonialismo à direita, o corporativismo à esquerda — foi imediata. E nem tão surpreendente. Afinal, a velha direita patrimonialista sempre foi parte central da classe dirigente no Brasil e está acostumada às formas clássicas da procura de vantagens e privilégios (nepotismo, clientelismo), assim como a velha esquerda corporativista é habituada às formas burocráticas da busca de privilégios, que incluem principalmente salários desvinculados do trabalho efetivo e aposentadorias sem relação com a contribuição previdenciária. Essa aliança, que tem em comum a luta autoritária pela autonomia da burocracia em relação à política, ficou evidenciada desde o primeiro voto, que coube à poderosa Comissão de Constituição e Justiça da Câmara, que decide sobre a admissibilidade constitucional de cada emenda: a velha direita patrimonialista e a esquerda corporativista votaram juntas para tentar derrotar a reforma. ${ }^{11}$

Uma vez que os adversários eram identificados, não hesitei em denunciá-los. Nesse caso, o acordo era impossível. Os políticos patrimonialistas defendem interesses pessoais ou familiares, os corporativistas, interesses de grupos. Os primeiros costumam organizar-se em grupos políticos locais, os segundos, em sindicatos. Mas ambos procuram vantagens e privilégios (rent-seeking): sua meta é capturar o patrimônio público, privatizar o Estado. Num primeiro momento, tentei persuadir representantes da velha esquerda, mas o diálogo não tardou a se mostrar impossível. Meu primeiro gesto como futuro ministro, em dezembro de 1994, antes da posse do novo governo, foi convidar para um almoço o presidente da Central Única dos Trabalhadores, Vicentinho da Silva. O convite foi recusado, como foram rejeitadas todas as minhas tentativas para apresentar o projeto aos deputados do Partido dos Trabalhadores — PT. Quando o projeto de emenda estava pronto, por volta de julho de 1995, apresentei-o às bancadas de todos os outros grandes partidos. Com o PT foi impossível. Embora, em particular, alguns representantes do PT concordassem com a maior parte das mudanças, a maioria discordava e até se recusava a debatê-las.

É preciso salientar, entretanto, que a responsabilidade pela inexistência de um verdadeiro debate público no Brasil não é apenas da oposição. Os representantes do governo, ao desqualificar as idéias da oposição, em vez de discuti-las, caem no mesmo erro. Falta no Brasil um 
common ground, um espaço público no qual o debate ocorra segundo regras aceitas por todos, a principal delas sendo o respeito pelo adversário. Essa é uma situação típica de democracias novas, como a brasileira, onde a intolerância se manifesta na crença de que o mundo está dividido entre o justo e o injusto, o certo e o errado, de que cada eleição é uma luta entre o bem e o mal, a salvação e a danação. Quando esse gênero de atitude é dominante, o debate é impossível, ou quase. Uma alternativa para o reformador é denunciar a incapacidade de debater dos adversários. Foi o que fiz. Mas, além disso, é esforçar-se por tornar o debate possível. É não recusá-lo nunca. É ter sempre argumentos ao invés de acusações. É evitar a todo custo observações pessoais ou explicações sociológicas ou psicanalíticas para as opiniões do adversários. Foi o que procurei fazer.

Ao mesmo tempo que identificava os adversários, eu precisava estabelecer alianças. Comecei apenas com a autorização do Presidente para propor o tema ao país, prossegui depois com o firme apoio dos governadores e dos prefeitos, além do apoio do Presidente e dos ministros da área econômica, embora estes vissem a reforma apenas como um instrumento para o ajuste fiscal. Meus aliados evidentes fora da administração eram os empresários, em decorrência do seu permanente conflito com a burocracia, mas esse apoio não era suficiente, uma vez que os empresários, apesar de seu poder econômico, pesam relativamente pouco no plano político, em um país onde a burocracia sempre foi tão forte: no século XIX e na Primeira República, com a burocracia patrimonialista clássica; desde a década de 30, com uma burocracia cada vez mais profissionalizada, mas sempre com uma burocracia poderosa. Precisava de um apoio político muito mais amplo.

Depois de um mês no cargo, descobri meus dois principais aliados: os prefeitos e os governadores. Eles sofriam diretamente os problemas administrativos e fiscais relacionados com o excesso de quadros e a impossibilidade de demitir, com o requisito constitucional do regime único de contratação para os servidores públicos que os tornava todos estatutários, com a autonomia do Poder Legislativo e principalmente do Poder Judiciário estadual para aumentar os próprios salários, com os salários abusivos de certos servidores (marajás), e particularmente com a dificuldade de exigir que todos os servidores trabalhassem, dado o requisito constitucional da estabilidade. Viajei pelo Brasil inteiro. Visitei governadores, participei de inúmeros congressos e encontros de prefeitos (temos mais de cinco mil municípios), para debater a reforma. $\mathrm{O}$ apoio deles foi crucial.

O resultado foi gratificante. Em julho de 1995, numa reunião de governadores com o Presidente no Palácio do Planalto, um deles, expressando o sentimento dos outros, disse: "A reforma administrativa é a reforma mais importante que o governo está propondo". Na verdade, a reforma da previdência social era mais importante em termos fiscais, uma vez que é 
nela que foram tratados os privilégios dos servidores relativos ao tempo

de serviço e ao valor da aposentadoria. Mas uma declaração desse tipo representava uma vitória política, sobretudo considerando que, nos últimos meses, a reforma havia recebido uma recepção fortemente negativa no país inteiro.

No caso dos governadores, a aliança não se reduziu a palavras; envolveu uma ação efetiva. Cada estado do Brasil tem um secretário de administração pública. Convidei todos para participarem da redação da emenda. Trouxeram a Brasília seus juristas, participaram de numerosas e demoradas reuniões e deram uma contribuição efetiva. Nos dois anos e meio que se seguiram, enquanto a emenda estava sendo examinada pelo Congresso, a participação dos secretários de administração manteve-se sempre ativa, procurando convencer os deputados dos seus estados.

\section{Obtendo o apoio dos altos funcionários}

Meu problema, no entanto, não era apenas obter a aprovação da emenda constitucional. Precisava também de que as idéias contidas no Plano Diretor recebessem a aprovação dos altos funcionários que seriam encarregados de aplicar a reforma. Portanto, o apoio desses funcionários era crucial, tanto para a aprovação da emenda constitucional quanto para a implementação do Plano Diretor. Pude contar, desde o início, com a ajuda de alguns deles para a elaboração da reforma. Formei uma equipe qualificada — baseada nos meus antigos alunos de Economia e Administração Pública da Fundação Getúlio Vargas, em São Paulo, alguns dos quais já se encontravam em Brasília, outros que eu trouxe quando fui nomeado, e em um grupo de servidores altamente qualificados que passei a conhecer ao chegar em Brasília, em janeiro de 1995. Essa equipe, que compartilhou comigo as novas idéias de forma entusiasmada, foi essencial para o êxito da reforma. Mas era preciso obter o apoio do conjunto dos altos funcionários.

Para tanto, precisava, em primeiro lugar, derrubar um preconceito que ameaçava desacreditar o meu trabalho. Segundo os adversários da reforma, eu seria "contra" os servidores, seria seu "carrasco". Como não "fazia parte deles", e uma vez que eu queria substituir a administração burocrática pela administração gerencial, eu desdenharia os servidores públicos. Ouvi falar muitas vezes que o apoio da burocracia era impossível. No início, até alguns amigos, como o Ministro da Saúde Adib Jatene, que mais tarde se tornaria um dos mais ativos defensores da reforma, partilhavam algumas dessas opiniões: na primeira semana do novo governo, ele declarou aos jornalistas, referindo-se à mudança da regra constitucional 
da estabilidade dos servidores, que eu, não sendo um servidor público, pouco entendia da administração pública.

Minha resposta a esse tipo de objeção sempre foi clara e direta: "Este apoio é possível e vou consegui-lo. A reforma gerencial não é contra os burocratas, e sim contra a administração pública burocrática. É contra uma forma de administrar o Estado que impede os altos funcionários de gerenciar, tomar decisões, escolher o melhor meio de lograr objetivos". Eu sabia que a minha ação e o meu discurso não raro confundiam as pessoas. Como poderia eu ser contra a administração pública burocrática e a favor de uma burocracia de Estado? Novamente, minha resposta era direta: "No Estado, preciso de gerentes para gerenciar, e esses gerentes são os servidores públicos, os burocratas. Eles precisam ter mais liberdade para decidir, não podem ficar presos a leis e regulamentos estritos, precisam adquirir novas competências e prestar mais contas à sociedade. Precisam poder tomar decisões, premiando e punindo, que motivem seus subordinados. Mas sempre serão burocratas do Estado, que exercem o poder em nome do Estado e dos políticos eleitos que lhes delegaram autoridade".

Nesta questão de ser contra ou a favor dos burocratas, minhas opiniões pessoais sempre foram claras. Tanto meu pai quanto minha mãe vinham de famílias de burocratas. Conheço bem o papel estratégico dos burocratas na formação e no desenvolvimento dos países. Não tenho dúvidas quanto à importância crucial do Estado, não apenas para garantir os direitos de propriedade, como também para proteger os direitos civis e sociais e promover o crescimento econômico e a competitividade internacional. Nunca teria aceito o cargo de Ministro da Administração Federal se pensasse de forma diferente. Posso ser crítico da burocracia e de certas formas de intervenção do Estado, assim como sou crítico do capitalismo e das falhas do mercado, mas da mesma forma que não faz sentido ser contra os empresários ou os gerentes da iniciativa privada, não faz sentido ser contra os servidores do Estado. Ambos desempenham papéis necessários para a sociedade. Durante o primeiro ano da reforma, foram freqüentes os preconceitos contra mim a esse respeito, em decorrência da minha experiência pessoal no setor privado e da permanente acusação de neoliberalismo feita pela oposição ao governo Fernando Henrique Cardoso. No entanto, não sentia dificuldade em debater essa questão com todos, em qualquer lugar. Às vezes persuadia meus interlocutores e sempre os surpreendia.

Dispunha de um poderoso instrumento de persuasão: o Plano Diretor. Não perdia oportunidade de apresentá-lo aos servidores, e sempre que o fiz, a recepção dos servidores públicos foi excelente: quando não era entusiasta, era positiva. Lembro que quando apresentei o Plano pela primeira vez na Câmara da Reforma do Estado, Martus Tavares, um dos servidores mais respeitados do Brasil, então Secretário-Executivo do Ministério do Planejamento e hoje Ministro do Planejamento, Orçamento e Gestão, disse 
que essa era a primeira proposta plenamente integrada e moderna para reformar a administração pública brasileira que havia visto. Antônio Anastasia, Secretário Executivo do Ministério do Trabalho, naquela ocasião, reagiu de forma semelhante e envolveu-se profundamente na elaboração da reforma, particularmente nos aspectos jurídicos da lei que criava as organizações sociais, apesar das enormes responsabilidades que ele tinha no seu próprio ministério.

Mas, além de debater e de me empenhar em persuadir os altos funcionários, tomei medidas concretas para conseguir seu apoio. Dei especial relevância ao conceito de carreiras típicas de Estado, que envolvem o uso do poder de Estado, como as carreiras de policiais, diplomatas, procuradores, fiscais, auditores, gestores e formuladores de políticas públicas etc. Constatei que essas carreiras são menos remuneradas que empregos semelhantes no setor privado, enquanto os servidores públicos comuns, de nível médio, ganham salários superiores em cerca de $50 \%$ aos salários do mercado. Portanto, embora aumentos salariais gerais tenham sido suspensos desde 1995, obtive vários aumentos para carreiras específicas. Menores do que eu esperava, dadas às limitações orçamentárias, porém suficientes para assinalar uma aliança.

Por outro lado, percebi que os concursos de ingresso nas carreiras de Estado não eram realizados de forma periódica. Algumas carreiras de Estado não recrutavam novos membros há vários anos. Quando se organizava um concurso, um grande número de candidatos era aprovado, e esta lista de aprovados servia para recrutar servidores durante muitos anos. Mudei tudo isso. Programei concursos para todas as carreiras de Estado, com previsão para os próximos três anos, definindo precisamente as datas, os conteúdos programáticos e o número de vagas. As carreiras de Estado contam hoje com um ingresso regular de novos membros, para compensar as aposentadorias. O serviço público estava sendo valorizado em termos concretos e visíveis.

\section{A luta no Congresso}

Embora eu contasse com a boa qualidade do desenho da reforma, houvesse obtido êxito em persuadir a opinião pública e as elites políticas e tivesse sido capaz de estabelecer alianças com governadores, prefeitos, empresários e altos funcionários, sabia que o verdadeiro desafio estava no Congresso. Foram necessários dois anos e meio para que o Congresso aprovasse a reforma. Em parte porque a reforma da previdência social, que fora apresentada antes, tinha precedência: a liderança do governo na Câmara dos Deputados só permitiu que a reforma da administração pública fosse adiante em 1997, quando ficou claro que ela reunira um consenso 
consideravelmente maior que a reforma da previdência. Também porque o

processo formal da aprovação de uma emenda constitucional é extremamente complexo e demorado. E sobretudo porque era necessário converter em apoio efetivo dos parlamentares o processo de persuasão realizado pelos debates e alianças estabelecidas na sociedade.

Essa não era uma tarefa fácil. Existe um debate intelectual entre os cientistas políticos brasileiros que é tão interessante quanto enganoso. De um lado está a visão dominante, segundo a qual a governabilidade é dificultada pelo sistema partidário e pelo sistema eleitoral (voto proporcional com listas abertas), que não produzem maiorias claras. Se acrescentarmos uma constituição pormenorizada e a exigência de uma maioria de 3/5 para reformar cada artigo, podemos ver como é difícil reformar a instituição-mor do Brasil. Do outro lado, dois pesquisadores questionaram recentemente essa idéia, apresentando um volume impressionante de dados que demonstram, primeiro, que os Presidentes conseguem geralmente fazer aprovar pelo Congresso a legislação de que precisam e, segundo, que o sistema político não é tão fragmentado como se pensa, uma vez que os votos seguem razoavelmente as linhas partidárias, que correspondem globalmente a tendências ideológicas. ${ }^{12}$

Em se tratando de um grande número de projetos de lei, e sobretudo de leis ordinárias, Figueiredo e Limongi estão provavelmente certos. Mas quando se trata de emendas constitucionais ou de leis que influem nos interesses de muitos, eliminam privilégios e permitem a transferência de recursos, a teoria da fragmentação aplica-se. Na Grã-Bretanha, a reforma gerencial foi institucionalizada com alguns documentos e apenas com um instrumento legislativo, facilmente aprovado pelo Parlamento britânico. Por contraste, no Brasil, mesmo com a confortável maioria de que dispõe o governo Fernando Henrique Cardoso, a aprovação de uma emenda constitucional é extremamente difícil. A maioria parlamentar é formada por uma coalizão heterogênea e indisciplinada de partidos, tornando necessários, além da aprovação da opinião pública, a realização de compromissos e o estabelecimento de alianças internas. Fiz as duas coisas nessa direção.

O principal compromisso que tive que fazer foi relacionado com o problema da demissão por excesso de quadros. Eu queria obter um mandato mais amplo a esse respeito para as três esferas de governo do Executivo (União, estados e municípios), mas isso se mostrou impossível. Fui obrigado a conceder que as demissões por excesso de quadros ocorreriam apenas quando os gastos com pessoal excedessem $60 \%$ do orçamento total. Já havia um dispositivo constitucional nesse sentido, a chamada Lei Camata, mas o Executivo não podia aplicá-la: a estabilidade era plenamente garantida. Com a aprovação da reforma constitucional, a plena estabilidade foi abolida, mas o excesso de quadros foi definido como excesso de despesas — o teto de $60 \%$ — e não como excesso de pessoal. 
Uma aliança interna interessante que estabeleci no Congresso foi

com os deputados dos estados que antes eram territórios da Federação. Esses estados têm um grande número de representantes no Congresso relativamente à sua população, e alguns contam, desde 1988, com servidores públicos pagos pelo Governo Federal. Conforme a Constituição de 1988, todos os servidores dos antigos territórios que estavam ativos na data de promulgação da Constituição, 3 de outubro de 1988, deveriam ser transformados em servidores públicos federais estatutários, passando a ser pagos pela União, embora a maioria deles fosse cedida para os novos estados. Não tardou a surgir um problema: quem era ativo naquela época? Cerca de mil pessoas foram deixadas numa área cinzenta e eram permanentemente ameaçadas de demissão. Os auditores do Tribunal de Contas - organização de controle externo do Congresso - pediam frequientemente a realização dessas demissões, que nunca ocorriam, seja porque esses servidores eram necessários, seja por causa da forte oposição dos deputados dos novos estados contra essa medida. Quando tomei posse, em janeiro de 1995, um conflito crônico presidia as relações entre o meu ministério, encarregado de controlar e demitir os servidores dos antigos territórios, e os deputados respectivos. Resolvi mudar a atitude do ministério em relação ao problema nos primeiros meses de minha gestão, porque tinha a convicção de que demitir aquelas pessoas não fazia sentido, dados dois argumentos: a situação jurídica era de fato confusa e muitos daqueles funcionários eram necessários. A situação, entretanto, permanecia indefinida juridicamente, e os deputados dos ex-territórios temiam que a qualquer momento demissões pudessem ocorrer. Um ano mais tarde, por ocasião da discussão da reforma na Câmara, alguns deles propuseram que um parágrafo no seu texto regulamentasse definitivamente o problema. Fiz o acordo, que apenas formalizava a política já em prática, e pude contar com um precioso número de votos adicionais no Congresso.

\section{Conclusão}

A aprovação pelo Congresso da emenda constitucional de reforma da administração pública brasileira e o apoio da opinião pública e da alta burocracia aos principais dispositivos e políticas contidos no Plano Diretor da Reforma do Aparelho de Estado constituem para mim uma história de sucesso. Um história que teve sucesso porque a reforma dispunha de um conteúdo claro e inovador, porque resultava de um debate democrático nacional que permitiu persuadir a opinião pública e integrar propostas adicionais, porque foram firmadas alianças políticas estratégicas com governadores e prefeitos, porque foi possível fazer acordos e aceitar compromissos que não colocaram em risco os objetivos visados. 
Em artigo apresentado em Chicago, a ser publicado em inglês, Melo (1998) compara o desempenho no Congresso das reformas administrativa, tributária e da previdência social. Ele ressalta duas causas que explicam o sucesso da reforma da administração pública: o apoio dos governadores e o meu empenho pessoal na defesa da reforma durante o debate nacional. Segundo ele, "a defesa de políticas torna-se difícil quando as lutas burocráticas internas são intensas e quando há uma fragmentação da liderança da reforma dentro do Executivo". No caso da reforma administrativa, entretanto, Melo entende que essa fragmentação foi evitada, porque ninguém jamais ignorou quem dirigia o processo. Nesse sentido, ele cita um editorial de O Estado de São Paulo, datado de 5 de maio de 1998, que afirma, comentando a aprovação da reforma pelo Congresso: “A vitória deve ser creditada à tenacidade do Ministro Bresser Pereira... e à sua capacidade de persuasão, que garantiram a quase total fidelidade ao texto original".

Essa opinião reflete duas regras que sempre me guiaram quando participei de governos: primeiro, quando a causa é boa, quando o que estou defendendo é central para a missão que estou executando, não me amedronto, mesmo sabendo que estou arriscando meu cargo; segundo, quando conto com um argumento claro, nunca desisto de convencer os demais e lograr o objetivo, quaisquer que sejam os obstáculos e as dificuldades.

Minha experiência no Ministério da Administração Federal e da Reforma do Estado do governo Fernando Henrique Cardoso foi a experiência pública mais gratificante da minha vida. Pude introduzir um novo tema na agenda política do país - a Reforma Gerencial Brasileira de 1995, apresentar um projeto e conseguir sua aprovação não apenas pelo Congresso Nacional, mas também por aqueles que deverão aplicá-la: os altos funcionários. Também pude lançar essas novas idéias no âmbito da América Latina. Fui por três anos, entre 1995 e 1997, presidente do CLAD - Centro Latinoamericano de Administración para el Desarollo - uma pequena organização multilateral dedicada à administração pública e sediada em Caracas, e depois disto, presidente do seu Conselho Científico. No quarto ano, seu Conselho Diretor, formado pelos ministros da administração dos 26 países membros, aprovou um documento recomendando formalmente a adoção de reformas gerenciais. ${ }^{13}$

Sei que ainda há muito a fazer, mas como o Presidente reeleito Fernando Henrique Cardoso disse-me em dezembro de 1998, ao formar seu novo ministério e convidar-me para ocupar o cargo de Ministro da Ciência e Tecnologia, "o essencial da reforma administrativa já foi feito". O comentário deixou-me feliz, porém não se pode considerar de forma supérflua o problema da implementação da reforma. Há muito o que fazer nessa área. O Presidente está ciente disso. Para tornar a implementação 
mais efetiva, e seguindo uma recomendação minha, o Ministério da Adminis-

tração Federal e da Reforma do Estado foi fundido com o Ministério do Planejamento. Dessa forma, será possível vincular o orçamento com a reforma gerencial, tornando-a mais rápida e efetiva. Nos primeiros quatro anos do governo Fernando Henrique Cardoso, a implementação da reforma dependia apenas da persuasão; essa tarefa podia ser realizada pelo pequeno MARE. Nos outros quatro anos, a persuasão deverá ser acompanhada de autoridade executiva, da qual só o Ministério do Planejamento, Orçamento e Gestão — novo nome do ministério que fundiu o Ministério do Planejamento e o Ministério da Administração Federal e Reforma do Estado) — dispõe. ${ }^{14}$

Um dos grandes desafios do processo de implementação é envolver os funcionários subalternos. Nessa área, enfrentei enormes dificuldades desde o primeiro dia no cargo, quando o presidente da CUT se recusou a falar comigo. O sindicato que representa esses servidores em Brasília - ou, mais precisamente, os funcionários que não possuem sindicatos próprios - o SINDSEP, adotou desde o início uma atitude extremamente agressiva. Em julho de 1995, o sindicato lançou uma campanha, com grandes cartazes publicitários e anúncios na televisão, dizendo: "Bresser quer arrasar o serviço público. Quer acabar com a saúde pública e a educação pública e transformar o Estado em polícia.” Eu estava indignado. Nada era mais distante das minhas convicções e da minha história pessoal. Recebi várias vezes os representantes dos sindicatos de servidores - tanto os do SINDSEP quanto das carreiras típicas de Estado - na tentativa de estabelecer um diálogo. Expus francamente minhas idéias e limitações. Mas obviamente não falávamos a mesma língua. No entanto, não desisti. E, para minha surpresa, o clima era totalmente diferente quando, em dezembro de 1998, recebi em audiência os dirigentes do SINDSEP. Dessa vez, a conversa foi mais que cortês: embora marcando suas diferenças, demonstraram interesse em saber mais a respeito da reforma gerencial. Durante a reunião, percebi que eram novos dirigentes. Contaram-me que haviam sido recém-eleitos, eram também membros da CUT, mas haviam constituído a oposição interna dentro do sindicato. Saí da reunião com uma sensação de felicidade. Estávamos chegando a um terreno comum com os sindicatos de servidores, algum espaço público havia sido construído, a ação comunicativa habermasiana começava a ser possível, e nada importa mais para o avanço da democracia que isso. Existe hoje a possibilidade de obter o apoio dos funcionários subalternos na reforma.

A Reforma Gerencial Brasileira de 1995 de um lado foi feita, de outro está apenas começando no Brasil. Foi feita porque seus dispositivos básicos foram aprovados; está apenas começando porque sua implementação necessita de anos. Foi um privilégio para mim liderar essa reforma entre 1995 e 1998 como membro do governo Fernando Henrique 

do meu país foi uma experiência fascinante. Ao escrever esse artigo, espero que minhas reflexões possam ajudar os futuros reformadores a reconstruir o Estado, a torná-lo mais democrático e com maior capacidade de servir os cidadãos, e a tornar os servidores públicos, de um lado, mais autônomos para tomar decisões e mais responsabilizáveis perante a sociedade, e, de outro, mais eficazes e eficientes na defesa do interesse público.

Notas

${ }^{1}$ Chamarei a Reforma Gerencial da Administração Pública simplesmente de Reforma Gerencial de 1995, porque nesse ano foi aprovado o Plano Diretor e enviada para o Congresso a respectiva emenda constitucional. A reforma gerencial integra a segunda geração de reformas, junto com as reformas tributária e da previdência social. A liberalização do comércio e a privatização, que ganharam força no início da década de 90 , constituíram a primeira geração de reformas. A liberalização do comércio foi completada em 1994. A privatização das estatais competitivas foi concluída em 1996, já no governo Cardoso, e a privatização dos serviços quase-monopolistas - comunicações, ferrovias e portos — completou-se em 1998. O processo de privatização da energia foi então iniciado, mas há crescentes dúvidas e resistências a seu respeito, dado seu caráter monopolista.

2 Ver Ministério da Administração Federal e Reforma do Estado, MARE (1995). Ver também os Cadernos MARE da Reforma do Estado e os artigos publicados pela ENAP — Escola Nacional de Administração Pública —, principalmente na Revista do Serviço Público, e em Vera Petrucci e Letícia Schwarz, orgs. (1999). Os Cadernos podem ser obtidos no site www.mpo.gov.br. Os trabalhos mais relevantes de minha autoria sobre a reforma são: Da Administração Burocrática à Gerencial (1996a); Estratégia e Estrutura para um Novo Estado (1996b); Cidadania e Res Publica: A Emergência dos Direitos Republicanos (1997a); A Reforma do Estado nos Anos 90: Lógica e Mecanismos de Controle (1997b); Uma Reforma Gerencial da Administração Pública no Brasil (1998a); e o livro Reforma do Estado para a Cidadania (1998b).

3 A respeito da pesquisa entre formadores de opinião, ver Instituto de Estudos Políticos (1997); sobre a pesquisa entre funcionários de nível médio, ver ENAP (1998).

${ }^{4}$ Ver Bresser Pereira, 1997a. Este artigo, além de publicado na Revista de Filosofia Política, foi publicado em três revistas jurídicas: Revista Trimestral de Direito Público, Informação Legislativa e Revista de Direito Administrativo.

5 Ver Gill, 1998, publicado neste mesmo número da RSP.

6 Ver Eli Diniz, 1998: 33.

${ }^{7}$ A respeito da minha passagem pelo Ministério da Fazenda e, mais particularmente, da minha ação durante a crise da dívida, ver Bresser Pereira (1995). Deixei o ministério alguns meses depois, em dezembro de 1987, porque não havia conseguido implementar um ajuste fiscal fortemente necessário. No entanto, 14 meses depois, o Plano Brady adotou minhas duas principais propostas a respeito da dívida: securitização e desvinculação parcial, nas negociações entre o FMI e os bancos comerciais. 
${ }^{8}$ Em 1ํo de janeiro de 1999, saí do MARE para ocupar o Ministério da Ciência e Tecnologia no segundo governo Fernando Henrique, que então se iniciava. Nesse novo posto, procurei aplicar a mesma filosofia de debate público. Quando saí do governo, seis meses mais tarde, Renato de Oliveira, presidente da Andes, Associação Nacional de Professores Universitários, ligada à CUT, disse a Denis Rosenfield, que foi meu vice-presidente do CNPq, conforme me relatou este último, que "a minha saída do ministério era também a saída de um princípio público de discussão, ausente em outras esferas governamentais". $\mathrm{Na}$ verdade, fora do governo terei melhores condições de debater e encontrarei na oposição política pessoas como Renato de Oliveira, que já conhecem as regras do debate democrático e a sua importância para o país.

${ }^{9}$ Em relação a este último requisito, o papel desempenhado por Paulo Modesto foi fundamental. Para o desenvolvimento das idéias que constituem a reforma gerencial brasileira, tal como constam no Plano Diretor e na emenda, foi essencial a contribuição da minha equipe no Ministério, dirigida por Ângela Santana.

${ }^{10}$ Mais precisamente, conforme observou corretamente Paulo Modesto, o jurista que me assessorou na reforma: "As modificações foram secundárias nos temas focados no texto original, mas o texto foi ampliado com novos temas e uma extensa normatividade, muitas vezes contraditória e mal redigida, sobre o sistema de remuneração. Os novos temas desfocaram aspectos gerenciais da reforma, ressaltaram ainda mais os aspectos fiscais, criaram expectativas de aplicação difíceis de serem atendidas (exemplo clássico: a conjugação subsídios/teto/acumulações)". Na verdade, o texto original redigido por Paulo Modesto, e que era juridicamente preciso, a partir das adições feitas pelo relator Wellington Moreira Franco e pelos demais deputados, perdeu algo da precisão e tornou-se prescritivo — um velho problema da forma de legislar brasileira - em vez de simplesmente normativo.

${ }^{11}$ Utilizo o termo patrimonialista para designar as práticas políticas que misturaram o patrimônio privado e público numa base individual ou familiar, e o termo corporativista para descrever a mesma prática vinda de um grupo organizado ou associativo. Faço uma distinção entre práticas corporativistas e corporatistas, uma vez que as últimas não têm caráter pejorativo, referindo-se ao Estado social-democrata moderno, onde as relações entre capital e trabalho são politicamente negociadas e envolvem uma intermediação ativa do Estado.

${ }^{12}$ Ver Figueiredo e Limongi, 1994, 1995.

${ }^{13}$ Ver CLAD, 1998.

${ }^{14}$ Propus, como alternativa, a transformação do MARE em uma secretaria da Presidência com nível ministerial, como era antes a SAF - Secretaria da Administração Federal, e o envolvimento direto do Presidente na matéria, mas a alternativa adotada parecia-me melhor, dada a falta de tempo (e de interesse) do Presidente Fernando Henrique Cardoso pelas questões relacionadas com a execução ou a prática administrativa diária.

\section{Referências bibliográficas}

Bresser Pereira, Luiz Carlos. (1995), “A Turning Point in the Debt Crisis”, Revista de Economia Política, 19 (2) abril 1999. Originalmente publicado in São Paulo: Fundação Getúlio Vargas, Departamento de Economia, Texto para Discussão n ${ }^{\circ} .48$, novembro. . (1996a), "Da Administração Pública Burocrática à Gerencial”, Revista do Serviço Público, 47 (1) janeiro. 
. (1996b), "Estratégia e Estrutura para um Novo Estado", Revista de

Economia Política 17 (3) julho 1997. Trabalho apresentado à Assembléia Geral Resumida das Nações Unidas sobre Administração Pública, outubro.

. (1997a), "Cidadania e Res Publica: A Emergência dos Direitos Republicanos", Revista de Filosofia Política . Nova Série, v. 1, Porto Alegre: Universidade Federal do Rio Grande do Sul, Departamento de Filosofia.

. (1997b), "A Reforma do Estado nos Anos 90: Lógica e Mecanismos

de Controle", Lua Nova - Revista de Cultura Política, n. 45, 1998. Publicada originalmente em Cadernos MARE da Reforma do Estado, n. 1, Brasília: Ministério da Administração Federal e Reforma do Estado, julho.

(1998a), "Uma Reforma Gerencial da Administração Pública no

Brasil”, Revista do Serviço Público, 49 (1), janeiro.

. (1998b), Reforma do Estado para a Cidadania. São Paulo: Editora 34/ENAP Escola Nacional de Administração Pública.

CLAD. (1998), Uma Nova Gestão Pública para a América Latina. Caracas: CLAD Centro Latinoamericano de Administración para el Desarrollo. Documento preparado pelo Conselho Científico e aprovado pelo Conselho Diretor do CLAD, 14 de outubro.

DinIz, Eli. (1998), "Uma Perspectiva Analítica para a Reforma do Estado", Lua Nova Revista de Cultura Política, n. 45.

ENAP. (1998), Conhecendo a Clientela da ENAP: O Perfil dos DAS 101.4, Relatório Síntese de Pesquisa. Brasília: ENAP- Escola Nacional de Administração Pública, março.

Figueiredo, Argelina Cheibub e Limongi, Fernando. (1994), "O Processo Legislativo e a Produção Legal no Congresso Pós-Constituinte". Novos Estudos Cebrap, n. 38, março. . (1995), "Mudança Constitucional, Desempenho do Legislativo e Consolidação Institucional", Revista Brasileira de Ciências Sociais, n. 29, outubro.

GLL, Indermit S.. (1998), "Some Determinants of Sustainable Public Administration Reform. Or, Why I am Optimistic about Administrative Reforms in Brazil". Trabalho preparado para o seminário "Public Reform in Brazil and the British Technical Cooperation" patrocinado pelo British Council. Londres. Brasília: The World Bank Brasilia Office, novembro.

Instituto de Estudos Políticos. (1997), "Os Formadores de Opinião no País e a Reforma do Estado". Brasília: Instituto Brasileiro de Estudos Políticos, fevereiro 1977.

Melo, Marcus André. (1998), "When Institutions Matter: The Politics of Administrative, Social Security, and Tax Reform in Brazil". Trabalho apresentado ao Congresso da LASA - Latin American Studies Association. Chicago, setembro. A ser publicado in Ben Ross Schneider e Blanca Heredia (orgs.). The Political Economy of Administrative Reform: State Building in Developing Countries.

Ministério da Administração Federal e Reforma do Estado (MARE). (1995), Plano Diretor da Reforma do Aparelho do Estado. Plano aprovado pela Câmara da Reforma do Estado da Presidência da República em setembro de 1995. Brasília: Imprensa Nacional, novembro.

Osborne, David e Gaebler, Ted. (1992), Reinventing Government. Reading, MA.: AddisonWesley.

Petrucci, Vera e Schwarz, Letícia (orgs.). (1999), Administração Pública Gerencial: A Reforma de 1995. Brasília: Editora da Universidade de Brasília/ENAP Escola Nacional de Administração Pública. 


\section{Reflexões sobre a reforma gerencial brasileira de 1995 \\ Luiz Carlos Bresser Pereira}

Neste trabalho o autor - Ministro da Administração Federal e Reforma do Estado no primeiro Governo Cardoso (1995-98) - pergunta-se por que, nesse período, a emenda constitucional que ficou chamada de Reforma Administrativa foi aprovada, enquanto que a Reforma Tributária e a Reforma da Previdência Social não o foram. Suas respostas são que a Reforma Administrativa (a) respondia a uma demanda social real; (b) possuía objetivos claros (tornar viável a Reforma Gerencial da administração pública burocrática brasileira); (c) tinha uma concepção precisa, particularmente em relação à proposta de mudança no direito à estabilidade; (d) envolveu alianças políticas e compromissos limitados; e (e) foi o resultado de um debate nacional que terminou por persuadir a opinião pública e os altos administradores públicos.

\section{Reflexiones sobre la reforma gerencial brasileña de 1995}

Luiz Carlos Bresser Pereira

En este trabajo el autor - Ministro de la Administración Federal y Reforma del Estado en el primer Gobierno Cardoso (1995-1998) - se pregunta porque, en aquel período, la enmienda constitucional que terminó siendo llamada Reforma Administrativa fue aprobada, mientras que la Reforma Tributaria y la Reforma de la Seguridad Social no lo fueron. Sus respuestas son que la Reforma Administrativa (a) respondía a una demanda social; (b) poseía objetivos claros (volver viable la Reforma Gerencial de la administración pública burocrática brasileña); (c) tenía una concepción exacta, en especial con respeto a la propuesta de cambio en el derecho a la estabilidad; (d) desarrolló alianzas políticas y compromisos limitados; y (e) fue el resultado de un debate nacional que terminó por convencerles a la opinión pública y a los altos administradores públicos.

\section{Reflections about the 1995 administrative reform in Brazil \\ Luiz Carlos Bresser Pereira}

In this paper the author - Minister of Federal Administration and Reform of the State in the first Cardoso Administration (1995-98) — asks himself why, in this period, the constitutional amendment that became known as the Administrative Reform, was approved by Congress, while the Tax Reform and the Social Security Reform were not. His answer is that the Administrative Reform (a) responded to a social demand; (b) had a clear objectives (to make viable the Managerial Reform of the Brazilian bureaucratic public administration); (c) presented a precise design, particularly on the proposed change of tenure rights; (d) involved political alliances and limited compromises; and (e) was the outcome of a national public debate, which ended by persuading public opinion and the Brazilian senior civil service.
Revista do

Serviço

Público

Ano 50

Número 4

Out-Dez 1999

Luiz Carlos

Bresser Pereira, professor titular de economia da Fundação Getúlio Vargas/SP e exMinistro da Administração e Reforma do Estado, da Ciência e Tecnologia e da Fazenda 